\title{
Elderly Patients with Metastatic Neuroendocrine Tumors Are Undertreated and Have Shorter Survival: The LyREMeNET Study
}

\author{
Annie Lemelin $^{\mathrm{a}} \quad$ Delphine Maucort-Boulch $^{\mathrm{b}, \mathrm{g}} \quad$ Elisabeth Castel-Kremer $^{\mathrm{c}}$ \\ Julien Forestier ${ }^{a} \quad$ Valérie Hervieu $^{\mathrm{d}, \mathrm{g}}$ Marianne Lorcet $^{\mathrm{a}}$ Florent Boutitie $^{\mathrm{b}}$ \\ Aurélie Theillaumas $^{a}$ Philip Robinson ${ }^{e}$ Antoine Duclos ${ }^{\mathrm{f}, \mathrm{g}}$ \\ Catherine Lombard-Bohas ${ }^{\mathrm{a}}$ Thomas Walter ${ }^{\mathrm{a}, \mathrm{g}}$

\begin{abstract}
a Service de Gastroentérologie et d'Oncologie Médicale, Hospices Civils de Lyon, Hôpital Edouard Herriot, Lyon, France; b Service de Biostatistique, Laboratoire de Biométrie et Biologie Evolutive, Equipe Biostatistique-Santé, Hospices Civils de Lyon, Université Lyon 1, Lyon, France; 'Service de Médecine Gériatrique, Hospices Civils de Lyon, Hôpital Edouard Herriot, Lyon, France; d Service Central d'Anatomie et Cytologie Pathologiques, Hospices Civils de Lyon, Hôpital Edouard Herriot, Lyon, France; ' DRCI, Hospices Civils de Lyon, Lyon, France; 'Service des Données de Santé, Hospices Civils de Lyon, Health Services and Performance Research lab (HESPER EA 7425), Lyon, France; gLyon 1 Claude Bernard University, Lyon, France
\end{abstract}

\section{Keywords}

Neuroendocrine tumor - Metastatic neuroendocrine tumor · Elderly · Prognosis · Treatment

\begin{abstract}
Introduction: The incidence of neuroendocrine tumors (NETs) is rising, especially in elderly patients. The elderly cancer population presents considerable challenges, yet little is known about the characteristics, treatment patterns, and outcomes of metastatic NET (mNET) patients. Methods: The Lyon Real-life Evidence in Metastatic NeuroEndocrine Tumors study (LyREMeNET, NCT03863106) included consecutive mNET patients, diagnosed between January 1990 and December 2017. The exclusion criteria were nonmetastatic NET, poorly differentiated neuroendocrine carcinoma, and mixed neuroendocrine-nonneuroendocrine neoplasms. We aimed to compare patients $\geq 70$ years old to patients $<70$ years old. Results: A total of 866 patients were included, 198 (23\%) were $\geq 70$ years old. There was no significant differ-
\end{abstract}

ence in characteristics except that elderly patients had synchronous metastasis more frequently. Elderly patients received significantly fewer treatments (median of 2.0 vs. 3.0 lines, respectively, $p<0.0001$ ), were significantly less frequently treated by chemotherapy (32 vs. $54 \%$ ), targeted therapy (16 vs. $30 \%$ ), peptide receptor radionuclide therapy ( 5 vs. $16 \%$ ), and they underwent significantly less frequently locoregional intervention. Median overall survival was significantly shorter in elderly patients (5.2 vs. 9.6 years). The most frequent cause of death was related to disease progression (71\%). Multivariate analysis found that, after adjustment for tumor location, tumor grade, and number of metastatic sites, age remained significantly associated with overall survival (HR 1.66, 95\% Cl 1.26-2.18), indicating a poorer survival in patients $\geq 70$ years old in comparison with younger patients $(p=0.0003)$. Conclusion: Patients $\geq 70$ years old have a worse survival, die frequently from their disease, and are undertreated compared to younger patients.

(c) 2019 S. Karger AG, Basel karger@karger.com

(C) 2019 S. Karger AG, Basel

www.karger.com/nen

Karger"
Thomas Walter

Service de Gastroentérologie et d'Oncologie Médicale, Hospices Civils de Lyon Hôpital Edouard Herriot, Pavillon E, UJOMM

FR-69437 Lyon Cedex 03 (France)

E-Mail thomas.walter@chu-lyon.fr 


\section{Introduction}

Neuroendocrine tumors (NETs) are rare and include a heterogeneous group of neoplasms derived from the gastrointestinal tract, the pancreas, and the lung. Their incidence is rising and, interestingly, the most important rise was noted in the population aged $>65$ years, among whom the incidence is estimated to be 25.3 per 100,000 person-years [1]. The median age of patients at diagnosis is 63.0 years [2], and a European register reported in 2010 that about $25 \%$ of NETs patients were $>75$ years old [3]. Moreover, recent results from the Surveillance, Epidemiology, and End Results (SEER) program [2] and from a Norwegian population-based study regarding the NET population showed that the median overall survival (OS) decreased with age, but the type of death was not reported [4]. However, we do not know whether patients die as a consequence of disease progression (suboptimal treatment or more aggressive disease) or due to comorbidities.

The older cancer population is heterogeneous and presents considerable challenges regarding cancer treatment that are related to comorbidities, frailty, and functional status. For instance, older patients with frailties, a state of vulnerability, are at increased risk of chemotherapy intolerance, postoperative complications, and mortality [5]. The risk/benefit ratio, therefore, needs to be carefully explored in order to personalize the optimal care strategy. On the one hand, overtreatment should be avoided in the elderly as this is likely to result in increasing toxicities and deterioration of quality of life, but, on the other hand, it is essential not to undertreat as this could lead to loss of chance in terms of prognosis. The current literature indicates that elderly patients with cancer tend to have delayed diagnosis and more often incomplete investigation, but also more often suboptimal treatment, especially regarding chemotherapy [6-9]. Another aspect to consider is that older patients are not specifically analyzed in clinical oncology trials [10-14]. For instance, in the main phase III studies in NETs, none specifically evaluated the elderly subgroup $\geq 70$ years old, although $26 \%$ of included patients were aged $\geq 65$ years old in the study investigating sunitinib in pancreatic NETs, as were $47 \%$ in the RADIANT-4 study investigating everolimus, and $25 \%$ of those included in the PROMID study investigating octreotide were above 68 years old [15-17]. These studies evaluated different subgroups of age for progression-free survival, but there are no specific data on the elderly subgroup. In consequence, generalizability and applicability of these main trials to the elderly population remain uncertain as well as the opti- mal management strategy to adopt in this frail population.

We, therefore, designed an observational study, the Lyon Real-life Evidence in Metastatic NeuroEndocrine Tumors study (LyREMeNET) to compare the clinical characteristics, treatment patterns, survival, causes of death, and prognostic factors of metastatic gastroenteropancreatic and lung NETs between patients $\geq 70$ years old and those $<70$ years old.

\section{Patients and Methods}

Patients with metastatic NETs (mNETs) were retrospectively selected from the neuroendocrine neoplasm database of the Hospices Civils de Lyon (Lyon, France), a center of excellence of the European NeuroEndocrine Tumours Society (ENETS). This study included patients with a diagnosis of mNETs, either synchronous or metachronous metastasis, made between January 1, 1990, and December 31, 2017, and seen at least once at the Hospices Civils de Lyon. The exclusion criteria were nonmetastatic NET, poorly differentiated neuroendocrine carcinoma, and mixed neuroendocrine-nonneuroendocrine neoplasms.

Data were collected from the medical charts and included demographic data, as well as tumor and treatment characteristics. NETs were classified using the most recent WHO classification available: gastroenteropancreatic NETs and other NETs were categorized using the WHO 2017 classification defined as NET G1, NET G2, NET G3, or undefined NET (when the diagnosis was made without tumor grade or Ki67 index [often before 2000]) [18]; WHO 2015 was used for lung NETs defined as typical carcinoid, atypical carcinoid, or undefined carcinoid (if data were not available or in the absence of a primary tumor specimen) [19]. For each treatment, initiation and discontinuation dates were registered in the database; this corresponds to a line of this treatment. Systemic treatments were clustered as somatostatin analog (SSA), chemotherapy, targeted therapy (everolimus or sunitinib), peptide receptor radionuclide therapy (PRRT), and interferon therapy. It should be noted that the same systemic treatment performed twice or more within a 6-month period was considered as the same line. Locoregional treatment included surgery (of the primary tumor or the metastases), liver embolization, radiological ablation, and endoscopic treatment. Two or more of the same type of locoregional treatments received within a 12 -month period were considered as the same line for analysis.

Causes of death for each patient were collected and categorized as related to disease progression, toxic death if death was related directly to a complication/consequence of mNET treatment within a 3-month period, unrelated to disease if the cause of death was not related to NET, or unknown if data were not found in the medical charts.

\section{Statistical Analysis}

Categorical variables were described as frequencies and percentages. Continuous variables were presented as medians and ranges. The $\chi^{2}$ or Fisher's exact tests were used to compare groups for qualitative variables, and a Mann-Whitney test was used for quantitative variables. 


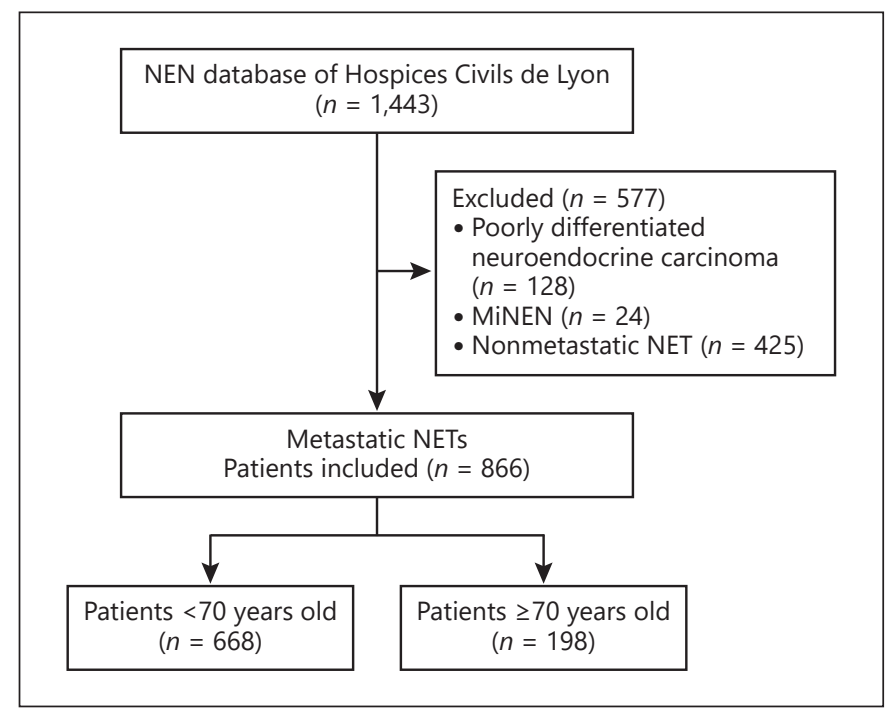

Fig. 1. Flow chart of the study population. NEN, neuroendocrine neoplasm; NET, neuroendocrine tumor; MiNEN, mixed neuroendocrine-nonneuroendocrine neoplasm.

OS was calculated from the date of metastatic diagnosis to the date of death or last follow-up. Disease-related survival (DS) was calculated from the date of metastatic diagnosis to the date of death due to disease progression. Survival curves for OS and DS were estimated using the Kaplan-Meier method. Estimated median and 5 -year survival rates are reported. The association of each factor with OS/DS was assessed using a Cox proportional hazards regression model on a univariate basis, yielding an estimate of the hazard ratio (HR) and its $95 \%$ confidence interval (CI), and a Wald $\chi^{2}$ test. The overall effect of each variable was tested with a log-likelihood ratio test. Proportional hazard assumption was tested with Schoenfeld residuals [20]. Multivariate analyses using a Cox proportional hazards regression model were also performed to identify factors independently associated with prognosis. All significant factors from the univariate analysis $(p<0.10)$ were included in the multivariate analyses; the final model included all such variables. A $p$ value of $<0.05$ was considered statistically significant. The results from the survival analyses are presented with the effect estimates, HR and 95\% CI. All analyses were performed using SAS Software version 9.4.

\section{Results}

\section{Patient Characteristics at the Time of $m N E T$ Diagnosis}

A total of 866 patients with mNETs were included in the study, among whom 198 (23\%) were $\geq 70$ years old (Fig. 1). There was no significant difference between the age groups regarding the location of the primary tumor, functioning status, the presence of genetic syndrome, the localization of metastasis, grade, and the period of diag-

Neuroendocrine Tumors in Elderly Patients nosis. Small-intestine and pancreatic NETs were the most frequent origin, and the majority of mNETs were classified as NET G1 or G2. Elderly patients presented significantly more frequently with synchronous mNETs than younger patients and with a shorter median interval between initial diagnosis of NET and metachronous metastasis (Table 1).

\section{Treatment Patterns}

Median (interquartile range) time from metastatic diagnosis to the first treatment was $1.8(0.7 ; 4.0)$ months. SSA was the most frequent first-line treatment in both age groups. Patients $\geq 70$ years old received significantly fewer lines of treatment than patients $<70$ years old ( $2.0 \mathrm{vs.}$ 3.0 lines in younger patients, $p<0.0001$ ); this was significant for both systemic and locoregional treatments. In addition, results demonstrated that patients $\geq 70$ years old received more frequently SSA as the first-line treatment $(77 \%)$ than patients $<70$ years old $(58 \%)$, but less frequently chemotherapy (18 vs. $37 \%$, respectively; Table 2).

During the course of their disease, elderly patients were significantly less frequently treated by chemotherapy (32 vs. $54 \%, p<0.0001$ ), PRRT ( 5 vs. $16 \%, p<0.0001$ ), and targeted therapy (16 vs. $30 \%, p=0.001$ ) than younger patients. Elderly patients also had undergone less frequently surgery of the primary tumor (50 vs. $71 \%, p<$ 0.0001 ), surgery of metastases ( 13 vs. $33 \%, p<0.0001$ ), and fewer elderly patients were treated by hepatic embolization (14 vs. $26 \%, p=0.0006$ ) or radiological ablation (1 vs. $6 \%, p=0.01$; Table 2 ).

\section{Prognostic Factors of OS and DS}

The median duration of follow-up since metastatic diagnosis was 48.3 months (range $0.0-417.4$ ) in the total population, 30.6 months (range $0.0-192$ ) in the population $\geq 70$ years old and 55.1 months (range $0.5-417.4$ ) in patients $<70$ years old. Among the total population, 330 (38\%) patients died during the period studied; 79 (40\%) patients $\geq 70$ years old and $251(38 \%)$ patients $<70$ years old. In both age groups, the most frequent cause of death was related to disease progression; in the total population, there were 233 deaths related to disease progression, 23 toxic deaths, 27 deaths unrelated to mNETs, and 47 deaths of unknown cause. Despite fewer deaths due to disease progression in patients $\geq 70$ years old, there was no significant difference in the cause of death between the 2 age groups ( $p=0.25$; Table 3 ).

Median OS was estimated to be 8.4 years in the total population and 5.2 years in patients $\geq 70$ years old, which 
Table 1. Patients' baseline characteristics at metastatic stage of neuroendocrine tumors

\begin{tabular}{|c|c|c|c|c|}
\hline & $\begin{array}{l}\text { Total population } \\
(n=866)\end{array}$ & $\begin{array}{l}\geq 70 \text { years old } \\
(n=198)\end{array}$ & $\begin{array}{l}<70 \text { years old } \\
(n=668)\end{array}$ & $p$ value \\
\hline Median age (range), years & $60(11-91)$ & $75(70-91)$ & $56(11-69)$ & \\
\hline Female, $n(\%)$ & $408(47.1)$ & $96(48.5)$ & $312(46.7)$ & 0.66 \\
\hline Primary site, $n(\%)$ & & & & 0.20 \\
\hline Small intestine & $383(44.2)$ & $92(46.5)$ & $291(43.6)$ & \\
\hline Pancreas & $289(33.4)$ & $57(28.8)$ & $232(34.7)$ & \\
\hline Lung & $100(11.6)$ & $23(11.6)$ & $77(11.5)$ & \\
\hline Other & $52(6.0)$ & $11(5.6)$ & $41(6.1)$ & \\
\hline Unknown & $42(4.8)$ & $15(7.6)$ & $27(4.0)$ & \\
\hline Functioning status, $n(\%)$ & & & & 0.53 \\
\hline Nonfunctioning & $436(50.4)$ & $104(52.5)$ & $332(49.7)$ & \\
\hline Carcinoid syndrome & $338(39.0)$ & $76(38.4)$ & $262(39.2)$ & \\
\hline Zollinger-Ellison & $32(3.7)$ & $4(2.0)$ & $28(4.2)$ & \\
\hline Other hormone release ${ }^{a}$ & $60(6.7)$ & $14(7.1)$ & $46(6.9)$ & \\
\hline Genetic syndrome $^{\mathrm{b}}, n(\%)$ & $18(2.1)$ & $1(0.5)$ & $17(2.6)$ & 0.09 \\
\hline Type of metastasis, $n(\%)$ & & & & 0.02 \\
\hline Synchronous metastasis & $660(76.2)$ & $158(79.8)$ & $502(75.2)$ & \\
\hline Metachronous metastasis & $199(23.0)$ & $36(18.2)$ & $163(24.4)$ & \\
\hline Locally advanced & $7(0.8)$ & $4(2.0)$ & $3(0.5)$ & \\
\hline Median time between metachronous metastasis & & & & \\
\hline and initial diagnosis (range), months & $37.5(1.8-439.3)$ & $26.4(7.5-146.1)$ & $43.6(1.8-439.3)$ & 0.01 \\
\hline Localization of metastases, $n(\%)$ & & & & \\
\hline Liver & $732(84.5)$ & $160(80.8)$ & $572(85.6)$ & 0.10 \\
\hline Distant lymph nodes & $269(31.1)$ & $62(31.3)$ & $207(31.0)$ & 0.93 \\
\hline Peritoneum & $201(23.2)$ & $47(23.7)$ & $154(23.1)$ & 0.84 \\
\hline Bone & $148(17.1)$ & $33(16.7)$ & $115(17.2)$ & 0.85 \\
\hline Lung & $73(8.4)$ & $15(7.6)$ & $58(8.7)$ & 0.62 \\
\hline Brain & $13(1.5)$ & $1(0.5)$ & $12(1.8)$ & 0.32 \\
\hline Other & $91(10.5)$ & $17(8.6)$ & $74(11.1)$ & 0.32 \\
\hline Number of metastatic sites at diagnosis, $n(\%)$ & & & & 0.59 \\
\hline 0 & $206(23.8)$ & $40(20.2)$ & $166(24.9)$ & \\
\hline 1 & $369(42.6)$ & $90(45.5)$ & $279(41.8)$ & \\
\hline 2 & $195(22.5)$ & $46(23.2)$ & $149(22.3)$ & \\
\hline$\geq 3$ & $96(11.1)$ & $22(11.1)$ & $74(11.1)$ & \\
\hline WHO classifications, $n(\%)$ & & & & 0.98 \\
\hline NET G1 or typical carcinoid & $213(24.6)$ & $49(24.8)$ & $164(24.6)$ & \\
\hline NET G2 or atypical carcinoid & $395(45.6)$ & $89(45.0)$ & $306(45.8)$ & \\
\hline NET G3 & $60(6.9)$ & $14(7.1)$ & $46(6.9)$ & \\
\hline Undefined NET or carcinoid & $198(22.9)$ & $46(23.2)$ & $152(22.8)$ & \\
\hline Patients with Ki67 index available, $n(\%)$ & $583(67.3)$ & $129(65.1)$ & $454(68.0)$ & \\
\hline Median Ki67 (range), \% & $5.0(0.0-70.0)$ & $5(0.0-60.0)$ & $5(0.0-70.0)$ & 0.89 \\
\hline Period of metastatic diagnosis, $n(\%)$ & & & & 0.23 \\
\hline$<2010$ & $439(50.7)$ & $93(47.0)$ & $346(51.8)$ & \\
\hline$\geq 2010$ & $427(49.3)$ & $105(53.0)$ & $322(48.2)$ & \\
\hline
\end{tabular}

WHO, World Health Organization; NET, neuroendocrine tumor; G, grade. ${ }^{\text {a }}$ Glucagonoma $n=21$, insulinoma $n=13$, vipoma $n=9$, parathyroid hormone-related protein $n=8$, Cushing $n=5$, other $n=4$. ${ }^{\text {b }}$ Multiple endocrine neoplasia type $1 n=14$, tuberous sclerosis complex $n=2$, neurofibromatosis type $1 n=1$.

was significantly shorter than in younger patients $(9.6$ years, $p<0.0001$; Fig. 2 ; Table 3 ). OS in patients $\geq 70$ years old was estimated to be $94 \%$ at 1 year, $87 \%$ at 2 years, and $53 \%$ at 5 years compared to 97,90 , and $74 \%$, respectively, among those $<70$ years old (Fig. 2a). Median DS was significantly longer in patients $<70$ years old than in patients $\geq 70$ years old ( 13.5 vs. 8.3 years; Fig. 2b). Other prognostic factors which were signifi- 
Table 2. Pattern of treatments received by patients with metastatic NET

\begin{tabular}{|c|c|c|c|c|}
\hline \multicolumn{5}{|l|}{ Number of lines of treatment (locoregional and systemic) } \\
\hline received per patient, median (range) & $2.0(0-19.0)$ & $2.0(0-9.0)$ & $3.0(0-19.0)$ & $<0.0001$ \\
\hline \multicolumn{5}{|l|}{ Number of systemic lines of treatment per } \\
\hline patient, median (range) & $2.00(0-12.0)$ & $1.00(0-9.0)$ & $2.00(0-12.0)$ & $<0.0001$ \\
\hline \multicolumn{5}{|l|}{ First-line treatment patterns } \\
\hline Total number of first-line systemic treatments received & 636 & 154 & 482 & \\
\hline Type of first-line systemic treatments, $n(\%)$ & & & & $<0.0001$ \\
\hline Somatostatin analog & $398(62.6)$ & $119(77.3)$ & $279(57.9)$ & \\
\hline Chemotherapy & $206(32.4)$ & $28(18.2)$ & $178(36.9)$ & \\
\hline Type of first-line locoregional treatment received, $n(\%)$ & & & & 0.19 \\
\hline Liver embolization & $22(12.7)$ & $3(14.3)$ & $19(12.5)$ & \\
\hline Surgery of metastases & $138(79.8)$ & $15(71.4)$ & $123(80.9)$ & \\
\hline Radiological ablation & $6(3.5)$ & $1(4.8)$ & $5(3.3)$ & \\
\hline Endoscopic treatment & $3(1.7)$ & - & $3(2.0)$ & \\
\hline Other surgery & $4(2.3)$ & $2(9.5)$ & $2(1.3)$ & \\
\hline \multicolumn{5}{|c|}{$\begin{array}{l}\text { Number of patients receiving at least one line of these locoregional or systemic treatments during follow-up } \\
\text { Systemic treatments during follow-up, } n(\%)\end{array}$} \\
\hline Somatostatin analog & $635(74.2)$ & $148(75.5)$ & $487(73.8)$ & 0.6285 \\
\hline Chemotherapy & $421(49.2)$ & $62(31.6)$ & $359(54.4)$ & $<0.0001$ \\
\hline Peptide receptor radionuclide therapy & $115(13.4)$ & $10(5.1)$ & $105(15.9)$ & $<0.0001$ \\
\hline
\end{tabular}

cantly associated with OS after univariate (online suppl. Table 1; for all online suppl. material, see www. karger.com/doi/10.1159/000503901) and multivariate analyses were the tumor site (Fig. 2c), the number of metastatic sites at mNET diagnosis, and the tumor grade (Fig. 2d; Table 4). Small-intestine NET was associated with a better median survival (11.9 [8.5-14.4] years) than pancreatic NET (7.6 [5.6-9.6] years), NET of other origin (7.4 [4.7-15.1] years), and lung NET (6.8 [5.08.4] years). Factors associated with DS were the same as those associated with OS; the point estimate for tumor site as well as the number of metastases at diagnosis were higher for DS (online suppl. Table 2; Table 4).

Neuroendocrine Tumors in Elderly Patients
Among 809 patients from whom information regarding first-line treatment was available (note that we excluded 32 patients who received another first-line systemic treatment; Table 2), the OS of patients treated by first-line SSA (398 patients, HR 1.87, 95\% CI 1.39-2.53, $p<0.0001)$ and chemotherapy (206 patients, HR 2.54, $95 \%$ CI 1.85-3.50, $p<0.0001$ ) was worse than the OS of the 173 patients who underwent a first-line locoregional treatment. However, this result has not been tested in multivariate analysis as the choice of the anti-tumoral treatment is directly influenced by patient and tumor characteristics, which were not, by definition, present at initial diagnosis of NET. 


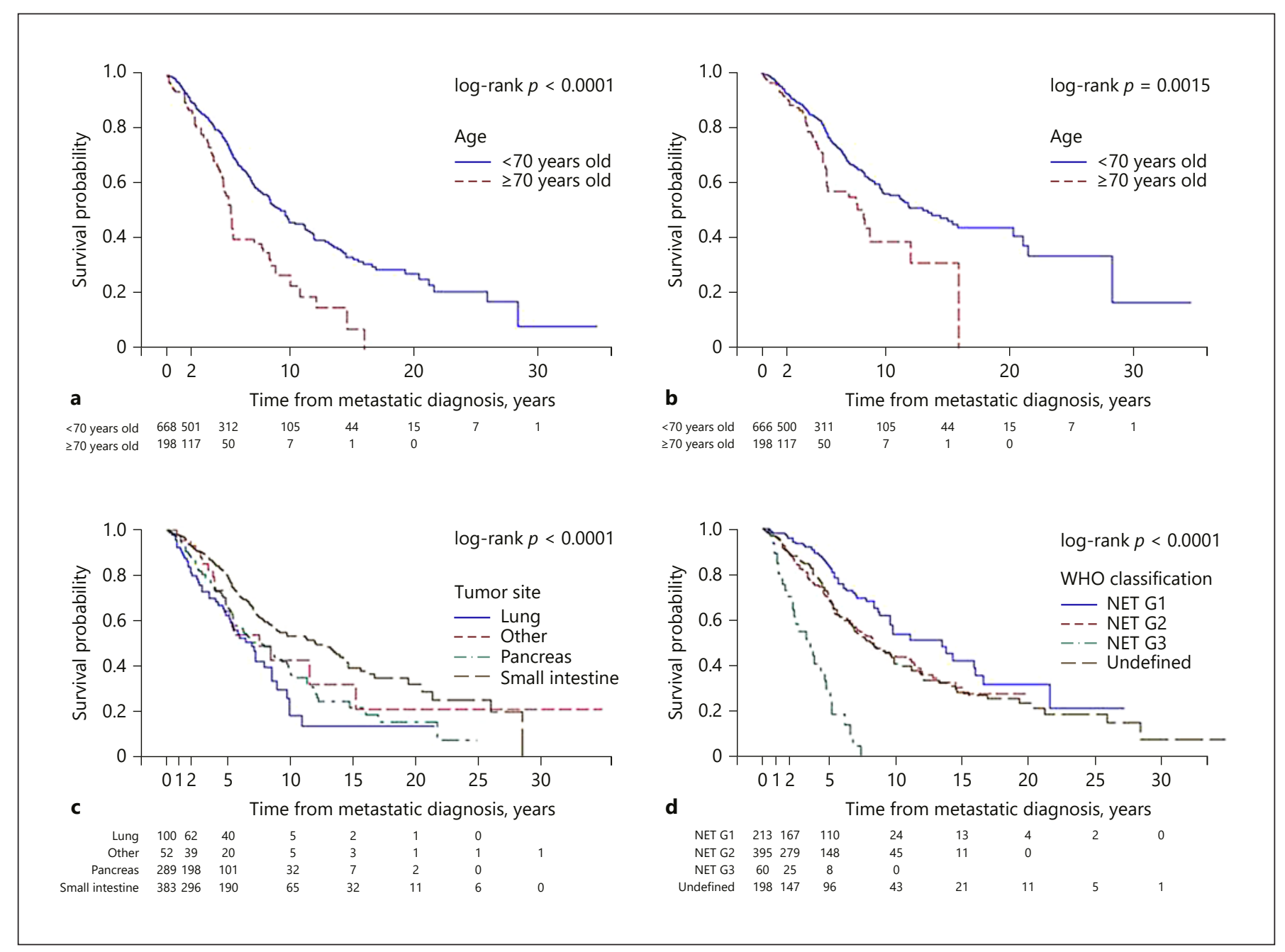

Fig. 2. Overall survival in years according to age groups (a); disease-related survival according to age groups (b); overall survival according to tumor site (c) and tumor grade (d). NET, neuroendocrine tumor; G, grade.

\section{Discussion}

The present study found that tumor characteristics were not significantly different between age groups, except for a higher proportion of synchronous disease among elderly patients. Despite this similarity (site, number of metastases, and WHO classification), age $\geq 70$ years old was a strong factor that impacted negatively on the prognosis. Moreover, the study found that the elderly population was undertreated, both in terms of systemic and locoregional treatments, resulting in fewer treatment lines offered to this age group during the course of their disease. The study also found that elderly patients, as did younger patients, died most frequently from disease progression and not from comorbidities or treatment complications.
The baseline characteristics of mNET patients were consistent with those previously reported; the majority of patients had a primary tumor in the small intestine or pancreas, a nonfunctioning tumor, and liver metastases [2]. Interestingly, although no significant difference was found herein when stratifying by age, it has recently been reported using results from the SEER database that the frequency of distant metastatic disease at diagnosis decreases in function of younger age (from $34 \%$ at age $>70$ years to $11 \%$ at age $\leq 20$ years), as does the frequency of grade 3 tumors (from $41 \%$ at age $>70$ years to $16 \%$ at age $\leq 20$ years) [2]. However, it should be noted that the SEER database also included poorly differentiated neuroendocrine carcinoma in the grade 3 category [2], which was not the case herein. 
Table 3. OS and causes of death

\begin{tabular}{|c|c|c|c|c|}
\hline & $\begin{array}{l}\text { Total population } \\
(n=866)\end{array}$ & $\begin{array}{l}\geq 70 \text { years old } \\
(n=198)\end{array}$ & $\begin{array}{l}<70 \text { years old } \\
(n=668)\end{array}$ & $p$ value \\
\hline Median OS (95\% CI), years & $8.4(7.6-9.7)$ & $5.2(4.6-7.1)$ & $9.6(8.3-11.2)$ & $<0.0001$ \\
\hline Median DS (95\% CI), years & $11.9(9.7-15.5)$ & $8.3(5.8-12.1)$ & $13.5(10.4-20.4)$ & 0.0015 \\
\hline Death, $n(\%)$ & $330(38.1)$ & $79(39.9)$ & $251(37.6)$ & \\
\hline $\begin{array}{c}\text { Annual mortality }(95 \% \mathrm{CI}) \\
\text { per } 100 \text { patient-years }\end{array}$ & $7.28(6.53-81.3)$ & $10.87(8.58-137.6)$ & $6.68(5.90-7.56)$ & \\
\hline Disease progression & $233(70.6)$ & $49(62.0)$ & $184(73.3)$ & \\
\hline Toxic death & $23(7.0)$ & $6(7.6)$ & $17(6.7)$ & \\
\hline Unrelated disease & $27(8.2)$ & $9(11.4)$ & $18(7.1)$ & \\
\hline Unknown & $47(14.2)$ & $15(19.0)$ & $32(12.7)$ & \\
\hline $\begin{array}{l}\text { Annual disease-related mortality } \\
\quad(95 \% \mathrm{CI}) \text {, per } 100 \text { patient-years }\end{array}$ & $5.12(4.49-58.4)$ & $6.93(5.15-93.1)$ & $4.81(4.16-5.57)$ & \\
\hline
\end{tabular}

OS, overall survival; DS, disease-related survival; CI, confidence interval.

Table 4. Prognostic factors of overall survival and disease-related survival (multivariate Cox proportional model estimates of hazard ratio)

\begin{tabular}{|c|c|c|c|c|c|c|}
\hline Model & Characteristics & Comparison & $\mathrm{HR}$ & $95 \% \mathrm{CI}$ & $\begin{array}{l}\mathrm{HR} \\
p \text { value }^{\mathrm{b}}\end{array}$ & $\begin{array}{l}\text { Global } \\
p \text { value }^{c}\end{array}$ \\
\hline \multirow[t]{9}{*}{ Overall survival } & Age & $\geq 70$ vs. $<70$ years old & 1.65 & $1.23-2.22$ & 0.0008 & 0.0008 \\
\hline & \multirow{2}{*}{ Tumor site ${ }^{\mathrm{a}}$} & Lung vs. small intestine & 2.63 & $1.75-3.94$ & $<0.0001$ & \multirow{2}{*}{$<0.0001$} \\
\hline & & Other vs. small intestine & 1.27 & $0.69-2.32$ & 0.44 & \\
\hline & \multirow{2}{*}{$\begin{array}{l}\text { Number of metastatic } \\
\text { sites at diagnosis }\end{array}$} & 1 vs. 0 & 0.99 & $0.72-1.38$ & 0.97 & \multirow[t]{2}{*}{0.0002} \\
\hline & & $\geq 3$ vs. 0 & 1.90 & $1.27-2.85$ & 0.002 & \\
\hline & \multirow{2}{*}{ Functioning status } & Nonfunctioning vs. carcinoid syndrome & 0.96 & $0.66-1.40$ & 0.83 & \multirow[t]{2}{*}{0.50} \\
\hline & & $\begin{array}{l}\text { Other hormone release vs. carcinoid } \\
\text { syndrome }\end{array}$ & 0.75 & $0.44-1.30$ & 0.31 & \\
\hline & \multirow[t]{2}{*}{ WHO classification } & G2 vs. G1 & 1.39 & $1.00-1.93$ & 0.050 & \multirow[t]{2}{*}{$<0.0001$} \\
\hline & & G3 vs. G1 & 5.54 & $3.31-9.27$ & $<0.0001$ & \\
\hline \multirow{10}{*}{$\begin{array}{l}\text { Disease-related } \\
\text { survival }\end{array}$} & \multirow{2}{*}{ Tumor site ${ }^{\mathrm{a}}$} & Lung vs. small intestine & 3.32 & $2.04-5.42$ & $<0.0001$ & \multirow{2}{*}{$<0.0001$} \\
\hline & & Other vs. small intestine & 1.67 & $0.82-3.41$ & 0.16 & \\
\hline & \multirow{3}{*}{$\begin{array}{l}\text { Number of metastatic } \\
\text { sites at diagnosis }\end{array}$} & 1 vs. 0 & 0.95 & $0.65-1.41$ & 0.81 & \multirow{3}{*}{$<0.0001$} \\
\hline & & 2 vs. 0 & 1.86 & $1.23-2.80$ & 0.0032 & \\
\hline & & $\geq 3$ vs. 0 & 2.21 & $1.37-3.56$ & 0.0011 & \\
\hline & \multirow[t]{2}{*}{ Functioning status } & Nonfunctioning vs carcinoid syndrome & 0.92 & $0.57-1.48$ & 0.72 & \multirow[t]{2}{*}{0.74} \\
\hline & & $\begin{array}{l}\text { Other hormone release vs. carcinoid } \\
\text { syndrome }\end{array}$ & 0.79 & $0.41-1.49$ & 0.46 & \\
\hline & \multirow[t]{3}{*}{ WHO classification } & G2 vs. G1 & 1.40 & $0.94-2.09$ & 0.097 & \multirow[t]{3}{*}{$<0.0001$} \\
\hline & & G3 vs. G1 & 6.12 & $3.39-11.03$ & $<0.0001$ & \\
\hline & & Undefined vs. G1 & 1.50 & $0.97-2.31$ & 0.070 & \\
\hline
\end{tabular}

HR, hazard ratio; CI, confidence interval; G, grade; WHO, World Health Organization. ${ }^{\text {a }}$ The modality "unknown” was not considered for this analysis. ${ }^{\mathrm{b}}$ Wald test. ${ }^{\mathrm{c}}$ Likelihood ratio test.

Neuroendocrine Tumors in Elderly Patients 
To the best of our knowledge, the present study is the first to report that elderly mNET patients were undertreated compared to patients $<70$ years old, which could, at least in part, explain the poorer prognosis reported both herein and elsewhere for NET $[2,4]$. These results are also consistent with previously published studies in other types of cancer that report that elderly patients are likely to be undertreated [6-9]. The results herein indicate that first-line treatment tended to be less aggressive, resulting in more frequent first-line treatment with SSA and less frequent first-line chemotherapy, even though the disease seems to be at least as aggressive as that in younger patients. In addition, the present study found that during the course of their disease older patients had less frequently PRRT, a treatment that has shown a benefit in terms of survival and quality of life $[21,22]$. Elderly patients also received less frequently targeted therapy, another treatment that improves efficacy, which could be given at appropriate adapted doses depending on comorbidities $[15,16]$. Considering the increase in the incidence of NETs particularly in the elderly in addition to the aging of the global population, it is urgent to include more elderly patients in phase III clinical trials and to systematically evaluate this subgroup of patients.

We report a poorer prognosis in mNETs of an elderly population, which was also recently reported by a Norwegian population-based study; the authors found a 5-year relative survival rate of $89 \%$ in patients $<50$ years old versus $41 \%$ among patients $>80$ years old, a result that remained significant after adjusting for stage [4]. Regarding the prognostic factors of survival, and as expected from previously published studies [4, 23-26], we found that higher grade, advanced metastatic disease, and lung NETs were associated with a poorer prognosis. Furthermore, another key aspect of the present study is that we showed that elderly patients more frequently died from a cause related to disease progression as did younger patients, and that elderly patients did not die more often from treatment complications. These points should encourage us to discuss such cases in multidisciplinary tumor board meetings in the presence of geriatric oncology specialists to propose optimal adapted treatment, always considering the risk/benefit ratio, which could help to improve the poorer prognosis of this heterogeneous age group. To the best of our knowledge, there are no published data regarding the use of a frailty scale in elderly in the field of NETs. The role of the comprehensive geriatric assessment (CGA) in elderly NET patients may be worthwhile in order to determine the risk of dying from comorbidities or from the mNET, and to help clinicians determine the optimal strategy without undertreating elderly patients, as this is reported to influence treatment decision in about $21-49 \%$ of cases in other cancers $[27,28]$. One approach that is currently considered in our center is to systematically screen mNET patients over 70 years old who need an invasive treatment (surgery, liver embolization, etc.) with the G8 screening tool, a reputed tool used in other solid tumors, and to refer patients to a dedicated oncogeriatric team if the G8 score is below 14 for further assessment for frailty and CGA $[29,30]$. Considering the findings of the present study, we propose (1) to further promote the inclusion of elderly patients in clinical trials; (2) to systematically analyze the subgroup of patients over 70 years old in all phase III clinical trials, which could lead to a better assessment of their response to treatments; (3) to document tolerance and quality of life in this population; (4) to systematically document causes of death in both those above and under 70 years old (disease-related or toxic death); (5) to use tools to assess frailty in the elderly, such as CGA, which could help to identify those at higher risk of adverse events and to propose optimal adapted treatment (e.g., dose reduction). These aspects can be easily implemented, and it would be interesting in the future to conduct a dedicated trial in elderly patients with quality of life/safety as the primary objective, especially for those with metastatic small intestinal NET that often have a good natural history with a slow-growing slope.

The strengths of our study are the high number of mNET patients included in a context of a rare disease and the exhaustive data collected regarding treatment that allowed the detailed evaluation of treatment patterns. Another key element is that we were able to determine the specific cause of death. Limitations of the study were the retrospective design, the single-center design, and that we were unable to collect data on patient performance status and comorbidities, the safety/tolerance of treatments, or whether the treatment required dose adjustments. Another limitation was the lack of a central review of the pathological diagnosis when the Ki67 index was not yet systematically performed (i.e., before WHO classification 2010).

In conclusion, elderly patients with mNETs have a worse survival, die frequently from their disease, and are undertreated compared to younger patients. Optimization in management of the elderly mNET population is required.

\section{Statement of Ethics}

This study was conducted according to the World Medical Association Declaration of Helsinki. The database was approved by the national data protection commission (Commission nationale de l'informatique et des libertés, CNIL) on November 6, 2015 (No. 15-111), and the trial was registered on the clinicaltrials.gov website (NCT03863106). 


\section{Disclosure Statement}

The authors declare that they have no conflicts of interest.

\section{Funding Sources}

This study was supported by IPSEN Pharma.

\section{Author Contributions}

A.L., D.M.-B., F.B., A.D., and T.W. contributed to the study design. A.L., A.T., C.L.-B., E.C.-K., J.F., M.L., V.H., and T.W. collected the data (prospective database). D.M.-B. and F.B. made the statistical analyses. P.R. helped with editing and manuscript preparation. All authors have read the manuscript and have agreed with its submission.

\section{References}

1 Dasari A, Shen C, Halperin D, Zhao B, Zhou S, $\mathrm{Xu} \mathrm{Y}$, et al. Trends in the Incidence, Prevalence, and Survival Outcomes in Patients with Neuroendocrine Tumors in the United States. JAMA Oncol. 2017 Oct;3(10):1335-42.

2 Sackstein PE, O'Neil DS, Neugut AI, Chabot J, Fojo T. Epidemiologic trends in neuroendocrine tumors: an examination of incidence rates and survival of specific patient subgroups over the past 20 years. Semin Oncol. 2018 Aug; 45(4):249-58.

3 Lepage C, Ciccolallo L, De Angelis R, Bouvier AM, Faivre J, Gatta G; EUROCARE working group. European disparities in malignant digestive endocrine tumours survival. Int J Cancer. 2010 Jun;126(12):2928-34.

4 Boyar Cetinkaya R, Aagnes B, Myklebust TA, Thiis-Evensen E. Survival in neuroendocrine neoplasms; A report from a large Norwegian population-based study. Int J Cancer. 2018 Mar;142(6):1139-47.

5 Handforth C, Clegg A, Young C, Simpkins S, Seymour MT, Selby PJ, et al. The prevalence and outcomes of frailty in older cancer patients: a systematic review. Ann Oncol. 2015 Jun;26(6):1091-101.

6 Turner NJ, Haward RA, Mulley GP, Selby PJ. Cancer in old age-is it inadequately investigated and treated? BMJ. 1999 Jul;319(7205): 309-12.

7 Aparicio T, Navazesh A, Boutron I, Bouarioua N, Chosidow D, Mion M, et al. Half of elderly patients routinely treated for colorectal cancer receive a sub-standard treatment. Crit Rev Oncol Hematol. 2009 Sep;71(3):249-57.

8 Bouchardy C, Rapiti E, Fioretta G, Laissue P, Neyroud-Caspar I, Schäfer P, et al. Undertreatment strongly decreases prognosis of breast cancer in elderly women. J Clin Oncol. 2003 Oct;21(19):3580-7.

9 Vercelli M, Capocaccia R, Quaglia A, Casella C, Puppo A, Coebergh JW; The EUROCARE Working Group. Relative survival in elderly European cancer patients: evidence for health care inequalities. Crit Rev Oncol Hematol. 2000 Sep;35(3):161-79.

10 Talarico L, Chen G, Pazdur R. Enrollment of elderly patients in clinical trials for cancer drug registration: a 7-year experience by the US Food and Drug Administration. J Clin Oncol. 2004 Nov;22(22):4626-31.

11 Quaglia A, Tavilla A, Shack L, Brenner H, Janssen-Heijnen M, Allemani C, et al.; EUROCARE Working Group. The cancer survival gap between elderly and middle-aged patients in Europe is widening. Eur J Cancer. 2009 Apr; 45(6):1006-16.

12 Hutchins LF, Unger JM, Crowley JJ, Coltman CA Jr, Albain KS. Underrepresentation of patients 65 years of age or older in cancer-treatment trials. N Engl J Med. 1999 Dec;341(27): 2061-7.

13 Zulman DM, Sussman JB, Chen X, Cigolle CT, Blaum CS, Hayward RA. Examining the evidence: a systematic review of the inclusion and analysis of older adults in randomized controlled trials. J Gen Intern Med. 2011 Jul;26(7): 783-90.

14 Crome P, Lally F, Cherubini A, Oristrell J, Beswick AD, Clarfield AM, et al. Exclusion of older people from clinical trials: professional views from nine European countries participating in the PREDICT study. Drugs Aging. 2011 Aug;28(8):667-77.

15 Yao JC, Fazio N, Singh S, Buzzoni R, Carnaghi C, Wolin E, et al.; RAD001 in Advanced Neuroendocrine Tumours, Fourth Trial (RADIANT-4) Study Group. Everolimus for the treatment of advanced, non-functional neuroendocrine tumours of the lung or gastrointestinal tract (RADIANT-4): a randomised, placebo-controlled, phase 3 study. Lancet. 2016 Mar;387(10022):968-77.

16 Raymond E, Dahan L, Raoul JL, Bang YJ, Borbath I, Lombard-Bohas C, et al. Sunitinib malate for the treatment of pancreatic neuroendocrine tumors. N Engl J Med. 2011 Feb;364(6): 501-13.

17 Rinke A, Müller HH, Schade-Brittinger C, Klose KJ, Barth P, Wied M, et al.; PROMID Study Group. Placebo-controlled, doubleblind, prospective, randomized study on the effect of octreotide LAR in the control of tumor growth in patients with metastatic neuroendocrine midgut tumors: a report from the PROMID Study Group. J Clin Oncol. 2009 Oct; 27(28):4656-63.

18 Kim JY, Hong SM, Ro JY. Recent updates on grading and classification of neuroendocrine tumors. Ann Diagn Pathol. 2017 Aug;29:11-6.

19 Travis WD, Brambilla E, Nicholson AG, Yatabe Y, Austin JH, Beasley MB, et al.; WHO Panel. The 2015 World Health Organization Classification of Lung Tumors: Impact of Genetic, Clinical and Radiologic Advances Since the 2004 Classification. J Thorac Oncol. 2015 Sep;10(9):1243-60.

20 Schoenfeld D. Partial residuals for the proportional hazards regression model. Biometrika. 1982;69(1):239-41.
21 Strosberg J, El-Haddad G, Wolin E, Hendifar A, Yao J, Chasen B, et al.; NETTER-1 Trial Investigators. Phase 3 Trial of 177Lu-Dotatate for Midgut Neuroendocrine Tumors. N Engl J Med. 2017 Jan;376(2):125-35.

22 Strosberg J, Wolin E, Chasen B, Kulke M, Bushnell D, Caplin M, et al.; NETTER-1 Study Group. Health-Related Quality of Life in Patients With Progressive Midgut Neuroendocrine Tumors Treated With 177Lu-Dotatate in the Phase III NETTER-1 Trial. J Clin Oncol. 2018 Sep;36(25):2578-84.

23 Hauso O, Gustafsson BI, Kidd M, Waldum HL, Drozdov I, Chan AK, et al. Neuroendocrine tumor epidemiology: contrasting Norway and North America. Cancer. 2008 Nov;113(10): 2655-64.

24 Yao JC, Hassan M, Phan A, Dagohoy C, Leary $\mathrm{C}$, Mares JE, et al. One hundred years after "carcinoid": epidemiology of and prognostic factors for neuroendocrine tumors in 35,825 cases in the United States. J Clin Oncol. 2008 Jun;26(18):3063-72.

25 Modlin IM, Lye KD, Kidd M. A 5-decade analysis of 13,715 carcinoid tumors. Cancer. 2003 Feb;97(4):934-59.

26 van der Zwan JM, Trama A, Otter R, Larranaga N, Tavilla A, Marcos-Gragera R, et al. Rare neuroendocrine tumours: results of the surveillance of rare cancers in Europe project. Eur J Cancer. 2013 Jul;49(11):2565-78.

27 Chaïbi P, Magné N, Breton S, Chebib A, Watson S, Duron JJ, et al. Influence of geriatric consultation with comprehensive geriatric assessment on final therapeutic decision in elderly cancer patients. Crit Rev Oncol Hematol. 2011 Sep;79(3):302-7.

28 Caillet P, Canoui-Poitrine F, Vouriot J, Berle M, Reinald N, Krypciak S, et al. Comprehensive geriatric assessment in the decision-making process in elderly patients with cancer: ELCAPA study. J Clin Oncol. 2011 Sep;29(27): 3636-42.

29 Bellera CA, Rainfray M, Mathoulin-Pélissier S, Mertens C, Delva F, Fonck M, et al. Screening older cancer patients: first evaluation of the G-8 geriatric screening tool. Ann Oncol. 2012 Aug;23(8):2166-72.

30 Decoster L, Van Puyvelde K, Mohile S, Wedding U, Basso U, Colloca G, et al. Screening tools for multidimensional health problems warranting a geriatric assessment in older cancer patients: an update on SIOG recommendations. Ann Oncol. 2015 Feb;26(2):288300 .
Neuroendocrine Tumors in Elderly Patients
Neuroendocrinology 2020;110:653-661 DOI: $10.1159 / 000503901$ 